\title{
Design and Implementation of the Auxiliary Teaching Platform in Colleges and Universities under the Hierarchical Teaching based on Web
}

\author{
Yunfang Xie ${ }^{1, \mathrm{a}}$, Ruixi Wang ${ }^{2, \mathrm{~b}}$ and Li Chen ${ }^{1, \mathrm{c} *}$ \\ ${ }^{1}$ College of Mechanical and Electrical Engineering, Agricultural University of \\ Hebei, Baoding 071001, China \\ ${ }^{2}$ Tianjin Research Institute for Water Transport Engineering, M.O.T., Tianjin \\ 300456, China \\ axyf2001_2001xdw@163.com, ${ }^{b} 45472992 @ q q . c o m,{ }^{c}$ Chenli1st@163.com \\ *Li Chen
}

\begin{abstract}
This paper analyses the present situation and the trend of development of the assistant teaching system at home and abroad, and designs an auxiliary teaching platform suit for modern colleges and universities combined with stratified teaching mode. The teaching platform can afford students independent learning space and time, satisfying the personality choice of the students. The auxiliary teaching platform in Colleges and Universities based on Web has finally established a teaching service system model satisfying kinds of learning needs of teachers and students, which can make up the insufficiency of after lesson interactions of existing teaching mode, promote the communication between teachers and students and advance students' independent learning ability and enhance the quality of teaching. This platform has been designed by using the B/S mode, developed by using many techniques such as ASP. NET, JavaScript, Ajax, jQuery, Web Service, and the database uses the database of SQL Server2008 R2. The system test results show that the whole system has easy operating, friendly interface and easy maintenance, and the database has stable operation, fast performance and high data security.
\end{abstract}

Keywords: Auxiliary teaching platform, stratified teaching mode, SQL Server, ASP.NET

\section{Introduction}

With the technique's progress and the rapid development of computer network, internet is used in the educational domain quickly. In order to make people's learning progress free to the limit of region and time, and make the teaching resources shared in the maximum range, the network teaching platform comes into being.

Because of the characteristic of course character, most of the specialized courses in Colleges and Universities have the disadvantage of strong theorization, abstract content, difficulty to understand and a certain degree of depth and difficulty. The disadvantages of the traditional teaching method make the teaching pay attention to the knowledge transfer, but ignore the engineering problems and the related social background, without the training of students' learning interest and practical ability. After class, the opportunity of contact between teachers and students reduce rapidly, with the communications having weakness for the limit of time [1]. For the above

${ }^{*}$ Corresponding Author 
reasons, it is bound to affect the students' learning enthusiasm and reduce the quality of teaching.

However, the network teaching mode based on the internet has good interaction, whose process can get rid of the limit of time, and it can make the teaching resources shared in a large range [2-3]. Therefore, it makes the conventional Classroom model which dominated by teachers transformed to a new model dominated by students. In this new mode, students are free to choose learning content. So by using existing conditions and techniques, we can build a teaching system platform which can strengthen the network communication between teachers and students and complement each other with the classroom teaching and therefore make the classroom teaching and network teaching perfect combined.

In order to cultivate the talents who can meet the needs of the information age, and to strengthen their comprehensive national power and international competitiveness, countries all over the world are taking active measures to develop and promote the application of network technology in the communication and education between teachers and students. At present the developed countries such as the United States, the United Kingdom have carried out network education using network media and network teaching has gradually become an important teaching form in foreign universities, secondary schools and primary schools. Chinese Ministry of education also attaches great importance to the work of this area, and makes great efforts to organize the implementation of the New Century Excellent Course Construction Project, hoping to promote the application of advanced technology in the network. All of these will further promote the development of network teaching [4-6]. But at present, most of the information platforms built by Chinese colleges and universities are still in the initial stage with a simple use of various information tools. The network information system platform of colleges and universities is only used to publish some simple information and to provide students with scores of inquiries, and it doesn't have the function of online communication between teachers and students, learning self-test, data download, etc.,. In addition, most online courses still uses the traditional network programming, which makes the developed online courses unsatisfactory.

The auxiliary teaching platform designed in this paper is a non real time autonomous network teaching which is based on Web technology. It uses advanced interactive Web technology to organize the teaching resources to the relevant Web pages and provides interactive services such as resource sharing, online test, online communication, the backstage management and other functions by storing the resources in the web server by B / S mode [7]. The system can make up for the lack of communication between teachers and students in traditional teaching, and it can let teachers make more efficient teaching plans through the timely feedback of information. At the same time, by using this system, each student can login system learning and self-test whenever and wherever possible, and it can fully arouse students' learning enthusiasm and initiative, achieving the purpose of improving the quality of education and teaching efficiency.

\section{The Combination of Stratified Teaching Mode and Auxiliary Teaching Platform}

\subsection{The Conception of Stratified Teaching Mode}

The so-called stratified teaching mode is an individualizing teaching method which can promote the students' active development. It is proposed according to the personal differences of the students' learning and adopts instructional strategies of different levels. The stratified teaching mode emphasizes teaching students according to their aptitude, 
emphasizing on the premise of the students' individual difference, so it can reflects students' dominant role at utmost, laying foundations of training students' subject awareness. With the expanding of education strength, the enrollment of colleges and universities symbolizes a rising trend and the student ability is divided into different levels, so it is very necessary to teach students in accordance with their aptitude. Using stratified teaching mode to students is an effective measure to make all the students get progress together, and it is also an effective way to make the way of teaching students according to their aptitude implemented.

\subsection{The Advantage of Stratified Teaching}

The quality education turns in the direction of each variant individual and promotes their development according to each student's actual condition. The foothold of using stratified teaching in education is all the students' development and making everyone step forward on the basis of their original. It is very motivating to every student to carry out stratified teaching. It proposes different learning target of different levels to the students of different levels, makes each level find their own learning coordinate, and everyone can achieve success after making efforts.

\subsection{The Implementing Measure Combined Stratified Teaching with Auxiliary Teaching Platform}

Combining stratified teaching with online teaching platform is a new attempt. Stratification of teaching resources is an important link in stratified teaching mode, which provides students with kinds of information resources and let students grasp the ability of getting and using these resources. Teaching resources can use the resources in being, such as textbooks, extracurricular books, E-journals and network resources, and they can increase or decrease according to different actual situations. It is propitious to bring into full play the learning initiative, enthusiasm and pioneering spirit of students in different levels to provide students with different interest in different levels with second classroom apart from textbooks, inspiring students' learning interests.

The auxiliary teaching platform in Colleges and Universities based on Web designed in this paper has the characteristics of large information capacity, open and shareware. The students can learn easily online by the network guidance. A large number of information resources make the best use of media form of text, picture, video, audio, and classify the degree of difficulty of the information resources, letting the students choose according to their learning situation and interest. The open network environment will produce a great impression to the formation of personalized education, the development of students' creative thinking, the transformation of relations of elements of teaching process and the switching from examination-oriented education to quality-oriented education.

\section{The General Design of the System}

\subsection{The Architecture of the System}

The system is designed based on the frame of .net, whose logical structure is divided into three levels, respectively expressed as presentation layer, application logical layer and data layer, as shown in Figure 1. 


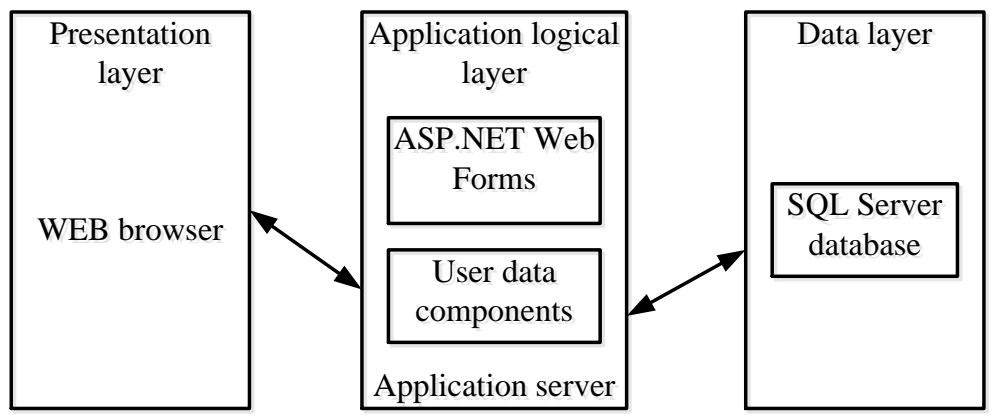

Figure 1. Logical Structure Diagram of the System

In the three-tier architecture of $\mathrm{B} / \mathrm{S}$, the client receives user request and makes requests to the server, getting data from the data base by using service, calculating data and submitting the results to the client. Then the client browser shows the results to the users. The $\mathrm{B} / \mathrm{S}$ architecture can be suit for the modern network teaching, especially to the situations of relative decentralization of the distance teaching students, to the disunity of the client configuration, to the bounded situation of the network transmission bandwidth and it is a background tool with the best advantage and developing future.

\subsection{Analysis of the System Users}

The auxiliary teaching platform system designed in this paper is oriented to the two roles of teachers and students. The functions of the system are as follows:

Teachers can achieve the following functions:

(1) Upload lesson plans: Teachers can upload lesson plans, curriculum materials, and according to certain classification method to classify the data, in order to facilitate students to learn to use and download.

(2)Data update: Teachers can add, modify and delete the contents of the course materials that they have released.

(3) Assign online homework: Teachers can organize the important teaching content into the homework, so that students can complete homework online and consolidate what they have learned.

(4) Test question management: Teachers can upload their own course related questions to the system test database, and can view the self testing results of students, master the learning situation of students, to help develop the teaching plan for the next step.

Students can achieve the following functions:

(1) Query Course materials: Students can view the public information about the curriculum, such as course introduction, curriculum outline, curriculum teaching plan, etc., that to enable students to learn selectively.

(2)Download and learn teacher lesson plans: After the students enter the platform, students can find the lesson plans they needed search to learn or download.

(3) Complete online homework: Students can finish the homework online, and transmitted to the system database, so that teachers marking.

(4)Test online: In each stage of learning, students can carry out self testing in the system, in order to understand their learning effect.

(5)Upload files: Students can upload documents about the course, such as case engineering, academic front, etc., for everyone to understand the development frontier of the course.

Second, the system can also achieve online communication, including online realtime communication, leaving a message, retrieving information database, etc.,. 
(1) Online real-time communication: When teachers and students online at the same time, the student can communicate the problem of learning with the teacher. When the teacher is not online, students can give a message to the teacher, and then when the teacher on the line, the teacher will be able to receive the message and give the answer.

(2) Retrieve information database: The main storage in the information database is the students' questions and the answers to the questions given by the teachers in their communication. When the student encounters the same problem, he can enter the information database to search by way of keyword search to find the solution to the problem.

(3)Managing discussion group: On line discussion will help students to understand some problems deeply. Teachers can further discussion some issues by setting up a discussion group.

\subsection{The Design of the System Function}

The design of the auxiliary teaching platform is divided into the following three modules: one is the teacher subsystem, the two is the student subsystem, and the three is the system management subsystem.

The main activities of teachers can be summarized as the operation of teachers, data maintenance, online communication and information release. Its specific structure function diagram is shown in Figure 2.

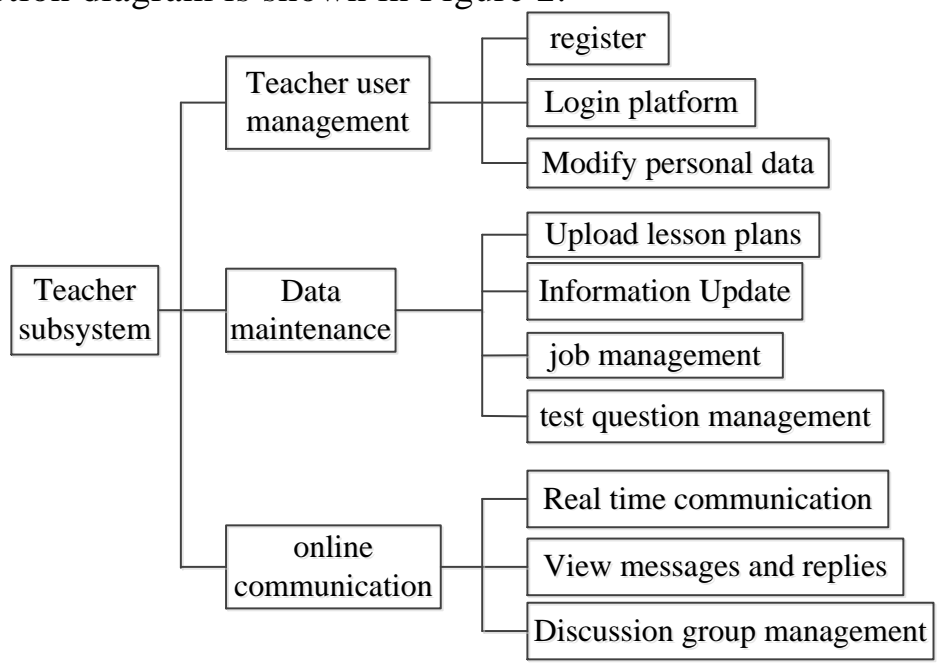

Figure 2. Function Structure Diagram of Teacher Subsystem

The main activities of students can be summarized as the operation of students, learning and exchange, viewing information and feedback. Its specific structure function diagram is shown in Figure 3.

The main job of system management is the maintenance of the information and the management of the system permissions.

(1) The maintenance of the information is the maintenance of the students' and teachers' essential information, including the addition and deletion of the users. It sorts out the teaching plans and the test questions uploaded by teachers and stores them in the database of the system, making the students' retrieval learning convenient. It also sorts out the information of mutual communication between teachers and students, expanding the information content of the information bank.

(2) The management of the system permissions is the situation that the system administrator can give different access according to different users. 


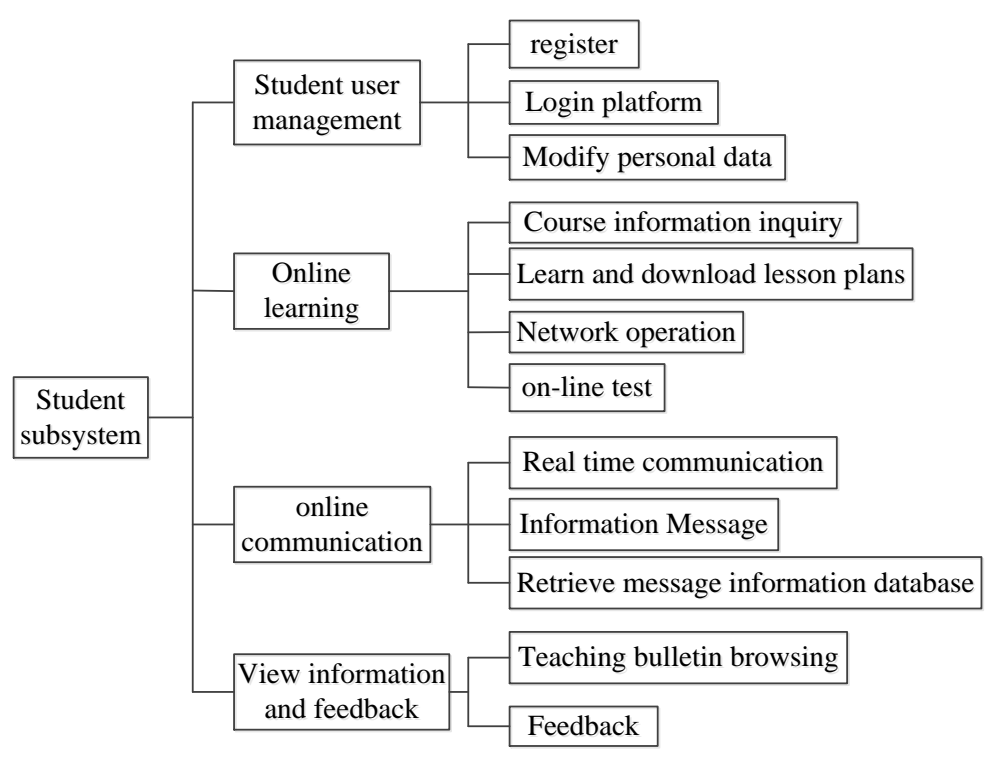

Figure 3. Function Structure Diagram of Student Subsystem

\subsection{Function Flow Chart of the System Platform}

Through the analysis of the function structure of the three parts of student subsystem, teacher subsystem and system management subsystem, the function flow of the system platform is obtained as shown in Figure 4.

System

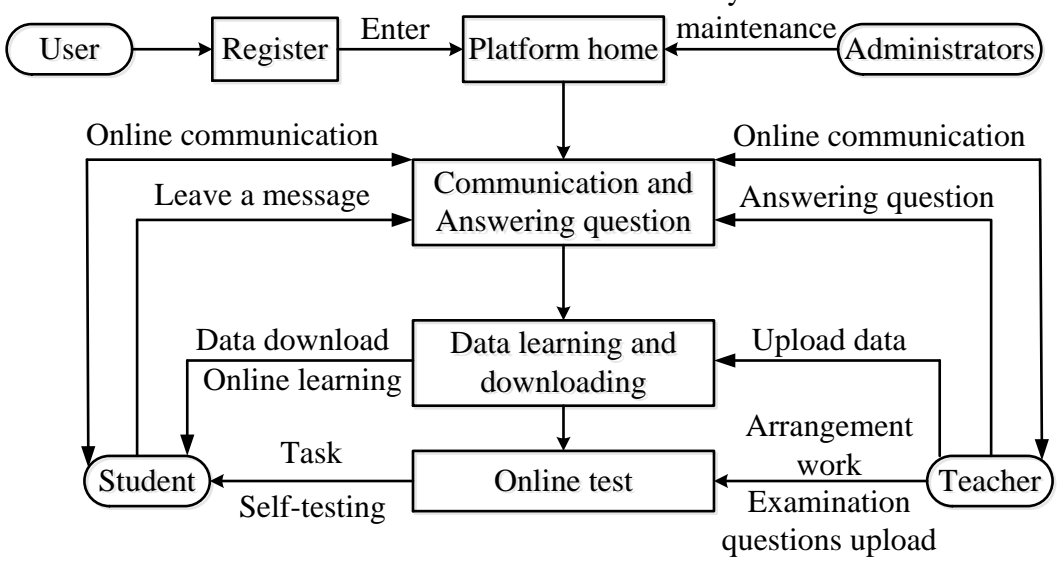

Figure 4. The Function Flow of the System Platform

\section{The Design and Implementation of the Auxiliary Teaching Platform}

\subsection{The Key Technology}

The platform uses B/S mode to develop, combed with other technologies such as ASP.NET, JavaScript, Ajax, jQuery, Web Service, etc., Its front page uses DIV+CSS standard web design and the whole system is developed by using ORM framework and the code generation tool. The System based on AOP architecture design ideas, so the code is more concise and late maintenance is more convenient [8-9]. The System is developed and implemented on the basis of the Microsoft's technology framework known as NET Framework Microsoft 4, and the Database uses Server2008 R2 SQL database. 


\subsection{The System Flow}

Users on the system home page can be registered, information release and other related operations. General flow chart of the system is shown in Figure 5.

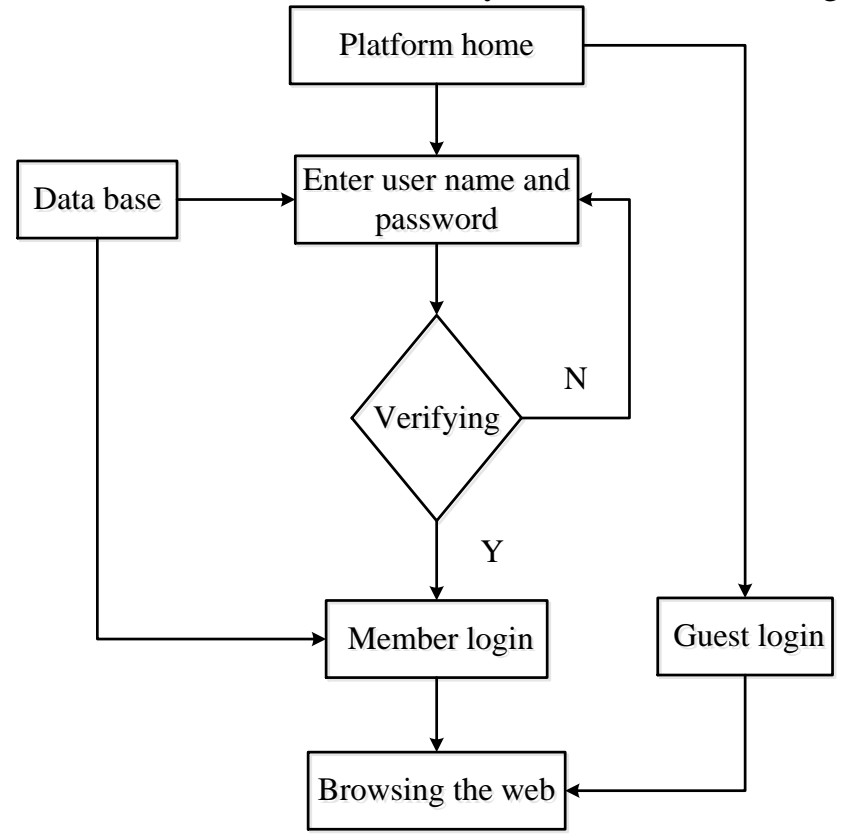

Figure 5. Flow Chart of the System

Ordinary users can directly open the system to browse the relevant information, but also can be registered as a system user. Registered users with the real name can find the teacher to communicate, so that the teacher can understand the user's learning progress and depth and other information. Registered users can also publish the theme, participate in the discussion and see the teacher's reply, etc.

\subsection{Data Flow Graph}

The user's needs are mainly reflected in the process of providing, inquiring, preserving and updating information. That requires the database can be more detailed and fully complete a variety of information to call and write. In the process of collecting basic data, data structure and data processing, a detailed data dictionary is formed in the database. The operation of the system's registered users will change the database. According to the operation process of the teachers and students, the data flow chart is designed as shown in Figure 6.

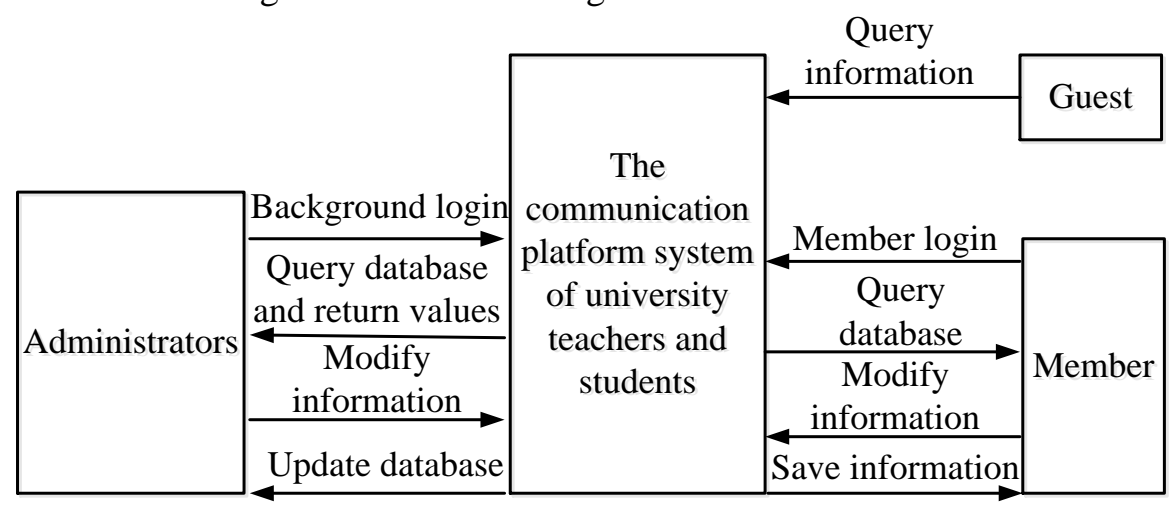

Figure 6. Data Flow Chart 


\subsection{The Main Interfaces of the System}

(1)Login interface (shown in Figure 7).

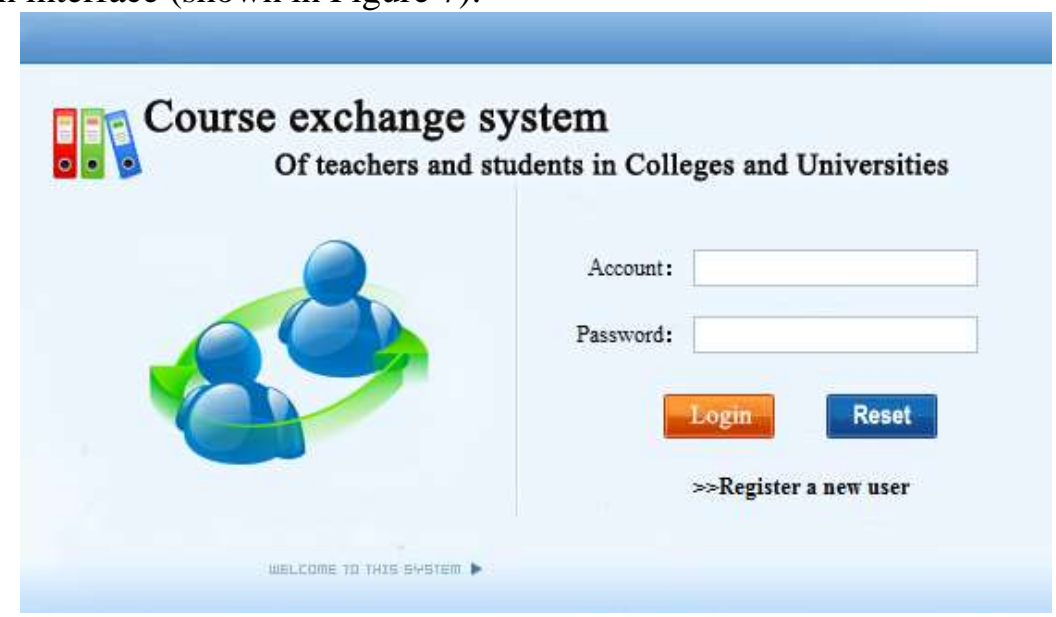

Figure 7. Login Interface

(2)Data upload interface (shown in Figure 8).

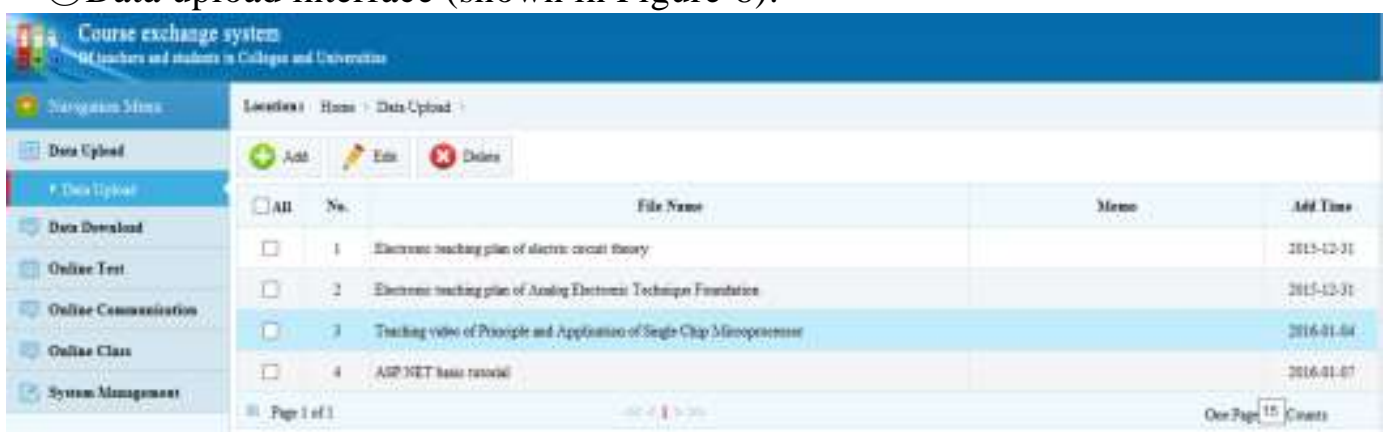

Figure 8. Data Upload Interface

(3)Data download interface (shown in Figure 9).

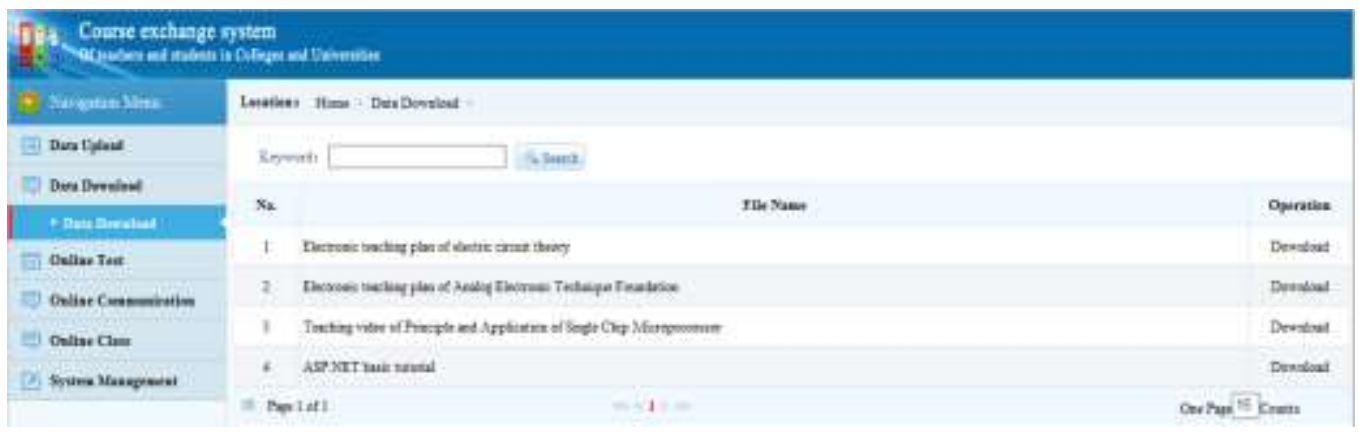

Figure 9. Data Download Interface

(4) Online test interface (shown in Figure 10). 


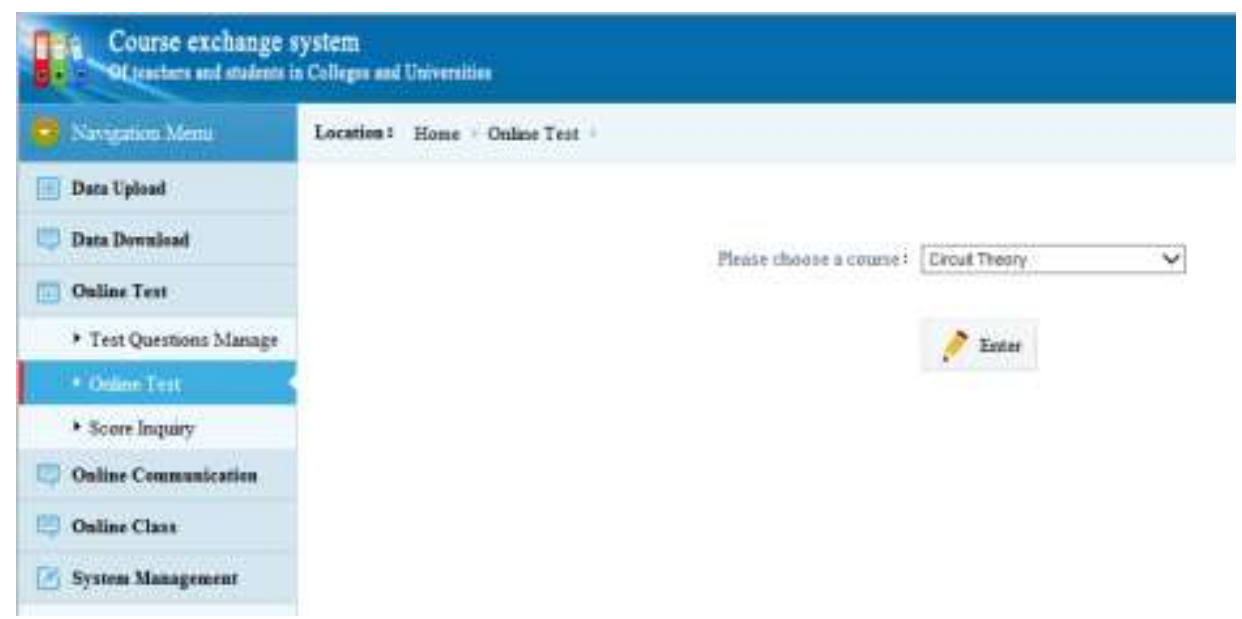

Figure 10. Online Test Interface

(5) Online communication interface (shown in Figure 11).

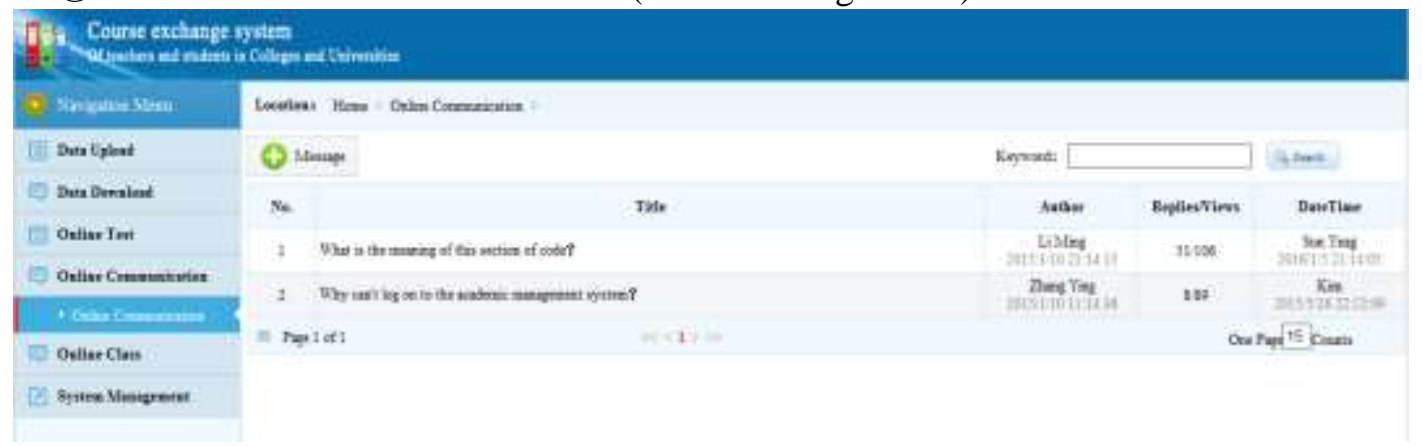

Figure 11. Online Communication Interface

(6) Online class interface (shown in Figure 12).

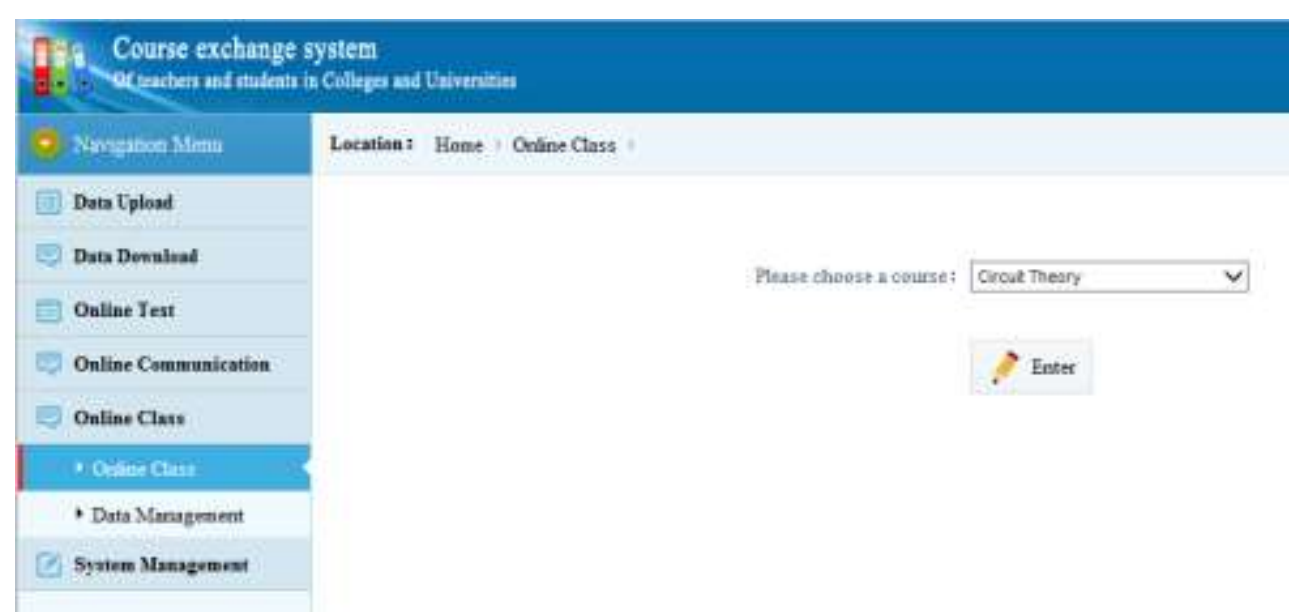

Figure 12. Online Class Interface

\section{Conclusions}

This paper has designed and brought out an auxiliary teaching platform in Colleges and Universities based on Web by analyzing the characteristics and needs of the teachers and students exchanging model in current colleges and universities, aiming at letting the teachers and students have a virtual community with complete function, and it has solved 
the bottleneck problem of the communication between teachers and students conveniently and effectively. This platform adopts the B/S model, has achieved the design based on Web by using active server pages, has finished the functions of mutual communication between teachers and students, resource sharing and on-line test, enriching the interaction pattern of teachers and students in colleges and universities efficiently. The technology used in this development project is in the lead, which has guaranteed the project's life cycle, provided the users with lasting and stable quality service, and has reduced the overall maintenance cost of the information system. The auxiliary teaching platform is used and tested, the results show that the system has the advantages of simple operation, friendly interface, easy maintenance, database operation stably, execution fast and high data security.

\section{Acknowledgements}

This work was supported by Baoding Science and Technology Research and Development Project (15ZG036) and Teaching Research Project of Agricultural University of Hebei (2015YB20, 2015YB19) and Humanities and Social Sciences Research project in Colleges and Universities of Hebei (GH161055).

\section{References}

[1]. Z. C. LI and L. ZHANG, "An Analysis of the Current Situation of the Relationship between College Students and Teacher and its Cause", Journal of Daxian Teachers College (Social Science Edition), vol. 14, no. 4, (2004), pp. 88-91.

[2]. H. FAN, "Analysis of Teaching Interactive Problems in Distance Education", Journal of Hubei Financial and Economic College, vol. 24, no. 1, (2012), pp. 82-83,

[3]. W. Yingbin, K. Yaohong, Y. Houqun, S. Xiaohong and Y. Ming, "Research of Computer Network Assisted Instruction System", NATURAL SCIENCE JOURNAL OF HAINAN UNIVERSITY, vol. 17, no. 3. (1999), pp. 246-249.

[4]. C. Li, "Information Exchange Activities and Student Interaction Network in Distance Learning", DISTANCE EDUCATION IN CHINA, no. 5, (2004), pp. 15-19.

[5]. K. Maly, C. M. Overstreet and A. Gonzalez, "Use of Web Technology for Interactive Remote Instruction”, COMPUTER NETWORKS AND ISDN SYSTEMS, vol. 30, no. 4, (1998), pp. 660662.

[6]. K. Sabry and L. Baldwin, "Web-based learning interaction and learning styles", British Jourmal of Educational Technology, vol. 34, no. 4, (2003), pp. 443-454.

[7]. T. Ren, "Software development technology based on B/S structure", XIDIAN UNIVERSITY PRESS, (2006).

[8]. J. Xiao, “ASP network programming technology”, TSINGHUA UNIVERSITY PRESS, (2001).

[9]. J. Tan and G. Zhang, "ASP website construction expert”, CHINA MACHINE PRESS, (2001).

\section{Authors}

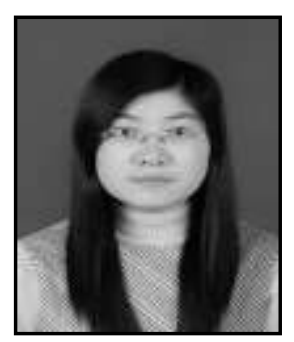

Yunfang Xie, (1982- ) Female. Lecturer. Research direction: The application of Artificial Intelligence in Power System. 